\title{
Modeling vapor intrusion processes and evaluating risks using subslab data
}

\author{
E. M. Suuberg ${ }^{1}$, Y. Yao ${ }^{1}$, R. Shen ${ }^{1}$, O. Bozkurt ${ }^{1} \&$ K. G. Pennell ${ }^{2}$ \\ ${ }^{1}$ School of Engineering, Brown University, Providence, USA \\ ${ }^{2}$ Department of Civil and Environmental Engineering, \\ University of Massachusetts, Dartmouth, USA
}

\begin{abstract}
This paper considers the significance of observed subslab contaminant concentrations on the vapor intrusion process. In field measurements, there is observed wide variability in the ratio of indoor air contaminant concentration to subslab contaminant concentration. Here various aspects of the relationship of subslab concentrations to indoor contaminant levels are explored using a threedimensional fluid dynamics model of the process. Subslab concentrations are determined mainly by diffusional processes and they are reasonably uniform across the subslab for buildings on homogeneous soils (with no significant advective subsurface disturbance). Also, subslab concentrations do not determine the main mode of contaminant entry into a structure (advection or diffusion), and widely different contaminant entry rates can be obtained with very similar subslab concentrations, depending upon whether the soil type supports advection or not.
\end{abstract}

Keywords: vapor intrusion, numerical modeling, subslab.

\section{Introduction}

One of the indoor air quality issues currently receiving increasing worldwide attention is that of vapor intrusion. The vapor intrusion problem is similar to that posed by radon, except that the source of the vapor in this case is anthropogenic, as opposed to natural. This also leads to differences in the nature of the phenomena. In non-radon vapor intrusion, the source is typically groundwater, and the problem is therefore often related to a plume of contaminated groundwater. Contaminants of concern include both chlorinated hydrocarbons 
and petroleum compounds. In the latter case, the problem may be partially naturally mitigated by biological activity.

This paper will describe some results obtained from a full three-dimensional fluid dynamics analysis of prototypical situations. A commercially available finite element code (COMSOL) is used to capture the essential physics of the problem. The results of modelling to date have shown that such quantitative modeling is necessary in order to understand the problem at a particular site, since quite often, real results contradict intuition $[1,2]$. The significance of soil geology, surface capping, "preferential pathways" and dynamic processes has all been illustrated. With such a code, it is possible to propose both better site investigation strategies as well as subsequent mitigation methods for existing or proposed buildings on contaminated sites.

Here, the focus is on the use of model results to inform the process of site investigation. Specifically, what are considered are the utility of so-called subslab contaminant vapor concentrations. These are generally obtained from within a structure suspected of being subject to a vapor intrusion impact. Figure 1 schematically shows the location of a subslab sample. Subslab measurements ordinarily involve boring a hole through the foundation slab of the structure, and taking a soil vapor sample from directly beneath that structure. Such measurements are clearly quite intrusive, particularly when residences or small commercial properties are the subject of investigation. Hence there is a desire to be judicious in their use and to make the most of these measurements. Among the argued advantages of such measurements is that they are the most indicative of the hazardous vapor concentration at a point immediately before entry to a structure in which measurement of concentrations can be confounded by factors such as variations in air exchange rates within the structure or background sources of the contaminant which have nothing to do with the vapor intrusion process itself.

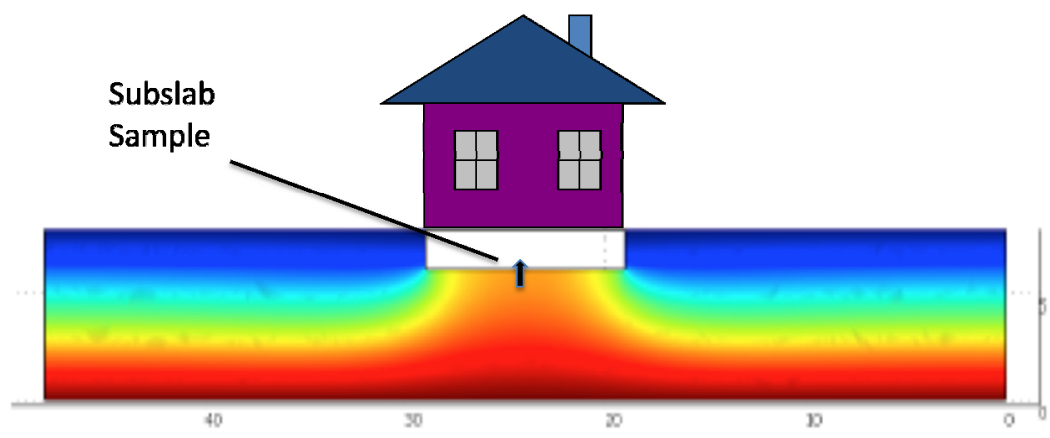

Figure 1: Structure sitting atop a homogeneous contaminant source in an otherwise open field. Colors indicate modelled contaminant concentration profiles, from high concentration at the source to zero concentration at the open surface. 
It is well established that contaminant concentration in soil gas sampled at a particular depth beneath a non-permeable cap on the soil (such as a foundation slab or a parking lot) would generally be higher than a sample taken at the same depth beneath open ground [2-4]. This is because the contaminant concentration profile in the subsurface is determined mainly by diffusion [e.g., 5, 6], and that inward advection into a structure mainly serves to enhance the entry of the underlying contaminant into the building, but does relatively less to distort the concentration profile in the soil. The contaminant concentration profile beneath the building is, however, very much that which would be expected from interposing an impermeable barrier somewhere in a diffusion field between a sink (the atmosphere) and the contaminant vapor source (the groundwater). Such a barrier "bottles up" the contaminant beneath it, and the concentration at that point begins to approach the concentration at the (groundwater) source; the only way for contaminant to escape from beneath the barrier is via slow lateral transport in the soil, governed by a small gradient. Thus the subslab contaminant vapor concentrations are normally expected to be the highest near-surface concentrations, and therefore, represent in some sense the highest potential indoor air concentrations. This result is seen in Figure 1.

The U.S. Environmental Protection Agency (USEPA) has assembled a significant database of vapor intrusion field measurements from a range of sites throughout the Unites States. This database (which may be freely accessed via the internet at http://www.epa.gov/oswer/vaporintrusion/vi_data.html) includes various types of contaminant vapor concentration measurements at many different sites. The data, for various contaminants of concern, include measurements of indoor air concentrations, subslab vapor concentrations, other soil gas concentrations and measurements and estimates of groundwater source concentrations. A preliminary evaluation of these data is available at http://www.envirogroup.com/publications/oswer_database report_combined 34-08 (2).pdf.

For present discussion purposes, it was interesting to examine this database in a way that is similar to that used by the USEPA, but with different constraints and representation of results. The values in the database were culled, choosing only at the data for one contaminant of concern, trichloroethylene (TCE). This was done to ensure that no artefacts are introduced by comparing across different compounds. The data were examined separately for structures built atop basements, slab on grade and crawlspaces.

Figure 2 shows the indoor air concentration in ratio to subslab concentration as a function of the particular structure's subslab concentration of TCE. This ratio of indoor to subslab concentrations clusters in a zone between 0.01 and 0.001 , once the subslab concentrations are above a range of about $100 \mu \mathrm{g} / \mathrm{m}^{3}$. The data in Figure 2 were plotted in the subslab concentration range from 20 to $2000 \mu \mathrm{g} / \mathrm{m}^{3}$ to emphasize the portion of the dataset that represents the bulk of the field data. At lower concentrations, the reported ratio was often greater than unity, indicating either a problem of data consistency or possibly the influence of background sources. The choice to emphasize midrange concentrations should not be taken to imply that there is no interest in lower ranges of concentration 
(which might still represent some health concern), but the focus here is in characterizing the transport aspects of the phenomenon, and the higher concentration level data afford this opportunity better than do the lower concentration level data where the above noted artefacts could play more of a role. The plot also demonstrates that the ratio of indoor to subslab concentrations is not materially dependent upon whether the data were taken from structures with basements or those involving slab-on-grade construction. While not shown here, data for crawlspaces were generally of the same order of magnitude as other indoor values.

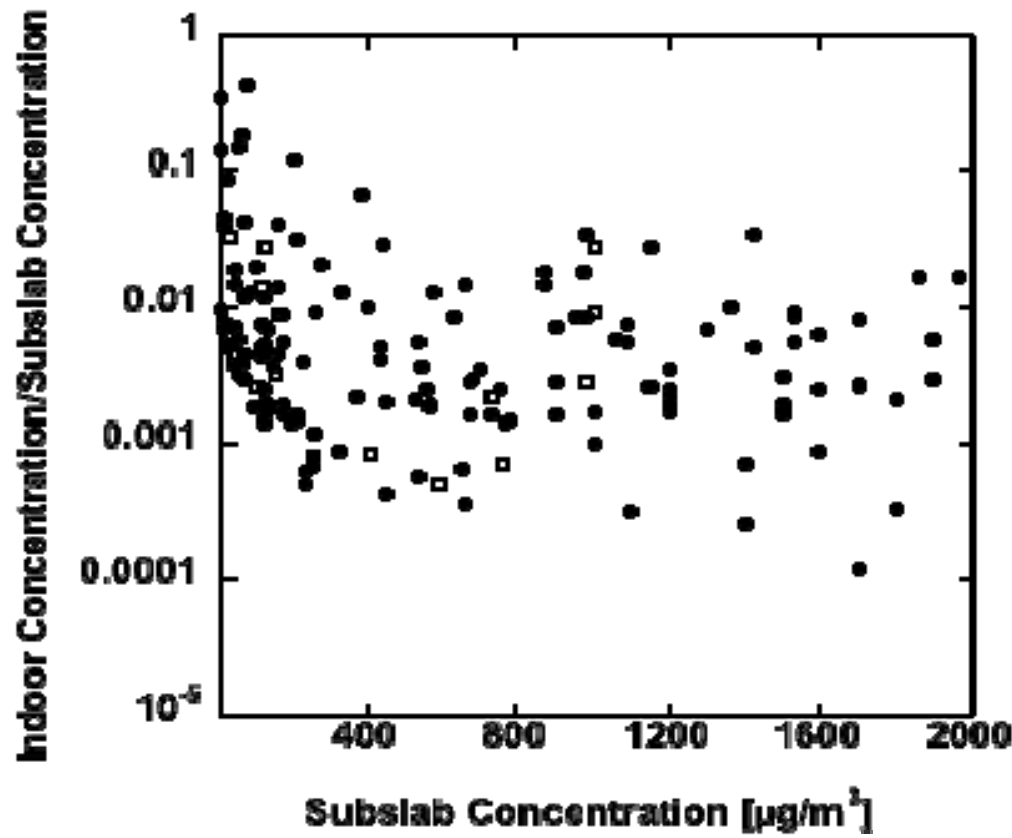

Figure 2: The ratio of measured indoor air contaminant concentration to measured subslab concentration (the "attenuation factor") as a function of subslab concentration.

The above indicates that there is a general similarity of results, to within an order of magnitude around a mean, for a wide range of buildings and sites. This is true over a great range of different soil and construction types. One critical factor that could not be well controlled in such studies was the indoor air exchange rate, and surely some portion of the variability must be attributable to that, as well as to a related building ventilation parameter, the negative interior pressure (from the so-called "chimney effect") that drives the inward advection of soil gas. 
There are numerous anecdotal reports of order of magnitude or greater variations in subslab contaminant concentrations, either when the same building is sampled at the same time at a number of points, or when the same building is sampled a number of different times at the same point, or when nearby buildings are sampled at the same time. Thus some portion of the variability of Figure 2 can likely be attributed to spatial variability due to heterogeneity in the underlying geology, but it is less likely that temporal variations are responsible, since in many cases, the data were taken concurrently.

The calculation of the entry rate of contaminant from the subslab into a structure needs to take into account a combination of diffusion and advection rates. The resulting indoor air concentration of contaminant is determined by what is shown as Equation 4 in Table 1 below, and depends upon the combined advective plus diffusive entry rate divided by the overall air entry rate into the relevant volume of the structure. The latter is determined by both the building air exchange rate and effective mixed volume of the structure in the area in which the contaminant is sampled. The air exchange rate is normally independent of the actual process of vapor intrusion, though it could be linked to the driving force for advective entry into the structure. There can in practice be quite large ranges in the values of both mixing volume and air exchange rate. As an illustration of the potential consequences of this fact, if both values were to be characterized by a factor of three variability, then almost an order of magnitude variability in the ordinate of Figure 2 would result. It is not claimed that the full variability of results in Figure 2 derives from this source alone, but it must be viewed as a potential key contributor, apart from any uncertainty regarding actual contaminant entry rates into the structure.

The remainder of this paper considers how results of subslab contaminant measurements can relate to the resulting indoor air concentrations. It does so by drawing upon the results of simulations of the vapor intrusion process, utilizing the full three-dimensional fluid dynamics simulation that has been presented in detail elsewhere $[1,2]$.

The present paper is only concerned with steady state conditions in cases where contaminant biodegradation plays no role. Clearly, transient processes can impact observed behavior, and the modeling work performed in this laboratory is considering these influences as well. Examples of factors that need to be considered in transient analyses include variations in source concentration with time, variations in groundwater character (e.g., the height of the water table, variations in soil moisture content), and variations in factors influencing vapor advection in the soil (such as changes in building pressure, effect of winds), Likewise, with certain classes of contaminants (especially petroleum-derived materials) there might be an impact of biodegradation processes on both steady state and transient contaminant vapor concentrations. Again, these processes are not considered here. 
Table 1: $\quad$ Working equations for model.

\begin{tabular}{|c|c|}
\hline $\begin{array}{l}\text { Equation 1: } \\
\text { Soil Gas Continuity } \\
q=\frac{k \rho_{g} \nabla \phi}{\mu_{g}} \\
\phi=g z+\int_{P_{0}}^{P} \frac{\nabla p}{\rho_{g}}\end{array}$ & $\begin{array}{l}q=\text { Gas velocity }(\mathrm{L} / \mathrm{t}) \\
k=\text { Intrinsic permeability }\left(\mathrm{L}^{2}\right) \\
\rho_{g}=\text { Density of soil gas }\left(\mathrm{M} / \mathrm{L}^{3}\right) \\
\mu_{g}=\text { Dynamic Viscosity soil gas }(\mathrm{M} / \mathrm{L} / \mathrm{t}) \\
g=\text { gravitational acceleration }\left(\mathrm{L} / \mathrm{t}^{2}\right) \\
p=\text { Pressure of soil gas }\left(\mathrm{M} / \mathrm{L} / \mathrm{t}^{2}\right) \\
z=\text { elevation }(\mathrm{L})\end{array}$ \\
\hline $\begin{array}{l}\text { Equation 2: } \\
\text { Pressure Drop Across } \\
\text { Foundation Crack } \\
\Delta p_{c k}=\frac{12 Q_{c k} \mu_{g} d_{c k}}{w_{c k}}\end{array}$ & $\begin{array}{l}\text { where: } \\
\Delta p_{c k}=\text { pressure drop across crack (assumes } \\
\text { parallel plates) }\left(\mathrm{M} / \mathrm{L} / \mathrm{t}^{2}\right) \\
w_{c k}=\text { Width of crack }(\mathrm{L}) \\
d_{c k}=\text { Length of crack through foundation } \\
\text { depth }(\mathrm{L}) \\
Q_{c k}=\text { Soil gas flow rate through crack into } \\
\text { building }\left(\mathrm{L}^{3} / \mathrm{t}\right)\end{array}$ \\
\hline $\begin{array}{l}\text { Equation 3: } \\
\text { Contaminant Transport } \\
J_{T}=q C-D_{i}^{g} \nabla C \\
D_{i}^{g}=D_{i}^{a i r} \frac{\eta_{g}^{10 / 3}}{\eta_{T}^{2}}+\frac{D_{i}^{w} \eta_{w}^{10 / 3}}{K_{H} \eta_{T}^{2}}\end{array}$ & $\begin{array}{l}\text { where: } \\
J_{T}=\text { Bulk mass flux of "i" }\left(\mathrm{M} / \mathrm{L}^{2} / \mathrm{t}\right) \\
C=\text { Concentration of " } \mathrm{i} \text { " in soil gas }\left(\mathrm{M} / \mathrm{L}^{3}\right) \\
D^{g}=\text { effective diffusivity of "i" in soil gas } \\
\text { phase }\left(\mathrm{L}^{2} / \mathrm{t}\right) \\
D_{i}^{\text {air }}=\text { molecular diffusion coefficient for } \\
\text { "i" in air }\left(\mathrm{L}^{2} / \mathrm{t}\right) \\
D_{i}{ }^{w}=\text { molecular diffusion coefficient for "i" } \\
\text { in water }\left(\mathrm{L}^{2} / \mathrm{t}\right) \\
K_{H}=\text { Air:water partition (Henry's) } \\
\text { coefficient (unitless) } \\
\eta=\text { porosity; } \mathrm{T}=\text { total, } \mathrm{g}=\text { gas-filled, } \\
\text { w=water-filled }\left(\mathrm{L}^{3} / \mathrm{L}^{3}\right)\end{array}$ \\
\hline $\begin{array}{l}\text { Equation 4: } \\
\text { Indoor Air Concentration } \\
C_{\text {indoor }}=\frac{A_{c k} J_{T}}{A_{e} V_{b}+Q_{c k}}\end{array}$ & $\begin{array}{l}\text { Contaminant transport across foundation: } \\
\begin{array}{l}J_{T}=q C_{c k}-D_{i}^{a i r} \nabla C_{c k} \\
\quad=\frac{q\left(C_{\text {indoor }}-C_{c k}\left(\exp \left(q d_{c k} / D_{i}^{a i r}\right)\right)\right)}{1-\exp \left(q d_{c k} / D_{i}^{a i r}\right)}\end{array} \\
\mathrm{C}_{\text {indoor }}=\text { Concentration of "i”" in the indoor air } \\
\left(\mathrm{M} / \mathrm{L}^{3}\right) \\
\mathrm{C}_{\mathrm{ck}}=\text { Concentration of " } \mathrm{i} \text { " entering foundation } \\
\text { crack }\left(\mathrm{M} / \mathrm{L}^{3}\right) \\
\mathrm{A}_{\mathrm{e}}=\text { Air exchange rate of building }(1 / \mathrm{t}) \\
\mathrm{V}_{\mathrm{b}}=\text { Volume of basement }\left(\mathrm{L}^{3}\right)\end{array}$ \\
\hline
\end{tabular}




\section{Modeling approach}

The modelling approach used here has been presented in more detail elsewhere $[1,2]$, and various results from this model have been published previously $[3,4]$. Other three-dimensional models of the vapor intrusion process have also been developed [6], and the results from these different approaches are in agreement on all key points. There are significant differences between the nature of, and predictions from, other widely used one-dimensional models of the process [7]. Reviews of various models of the vapor intrusion process have recently been published [8-10].

In the present finite element computational scheme, the first step is to define a domain, and represent it using a mesh that allows finer spacing at key points. Figure 3 shows a typical example of that which has been used in these studies. The equations that have been solved are shown in Table 1. The computational scheme here allows separate solution of Darcy's law for soil gas advection, and then subsequent solution of the contaminant diffusion-advection model. Further details are given in [2].

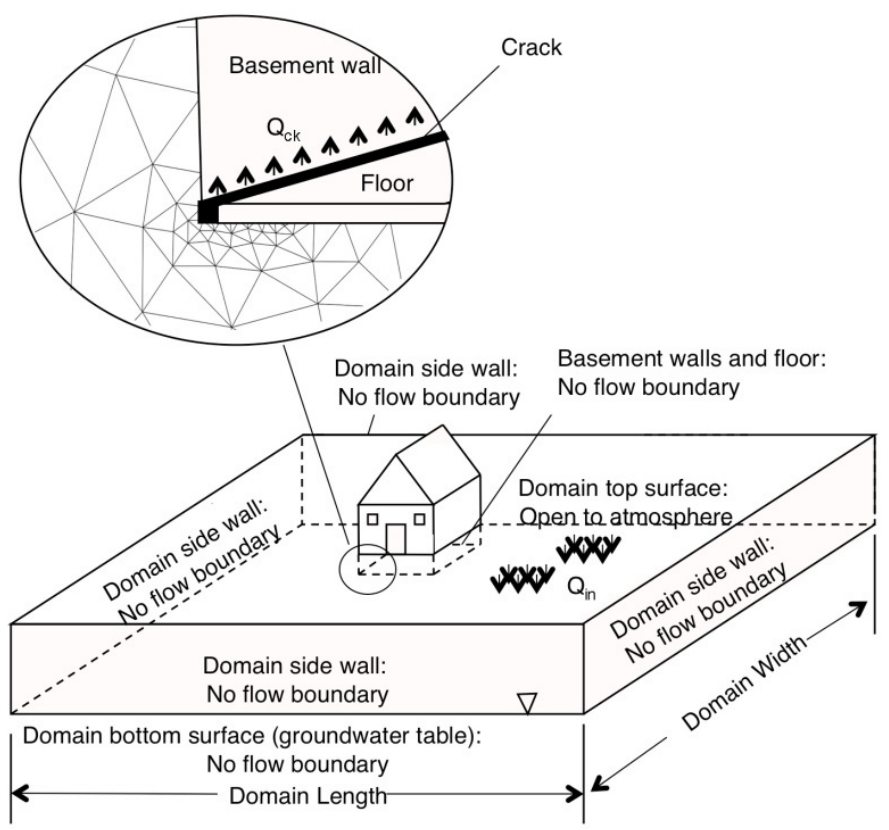

Figure 3: Simplified vapor intrusion model domain, showing domain boundary conditions. The model situation portrayed is a "perimeter crack" where the foundation walls meet the foundation slab. The inset figure shows the reduction in mesh size as the critical crack area is approached. Adapted from Pennell et al. [2]. 


\section{Results}

In the cases of interest here, the soil permeability $(k)$ was explored in a "typical" range of $10^{-10}$ to $10^{-14} \mathrm{~m}^{2}$, diffusivities $\left(D^{g}{ }_{i}\right)$ were in the range of $4 \times 10^{-7}$ to $1 \times 10^{-6} \mathrm{~m}^{2} / \mathrm{s}$. Water filled porosities $\left(\eta_{\mathrm{w}}\right)$ were in the range 0.03 to 0.19 for soils with total porosities $\left(\eta_{\mathrm{T}}\right)$ in the range 0.35 to 0.45 . A foundation size of $10 \mathrm{~m} \mathrm{x}$ $10 \mathrm{~m}$, with an in-ground depth of $2 \mathrm{~m}$ was taken as the base case.

Figure 4 shows the ratio of the predicted contaminant concentration at a perimeter crack of the foundation, as compared with the concentration of the contaminant at the center of the slab. The values are shown for three typical soil

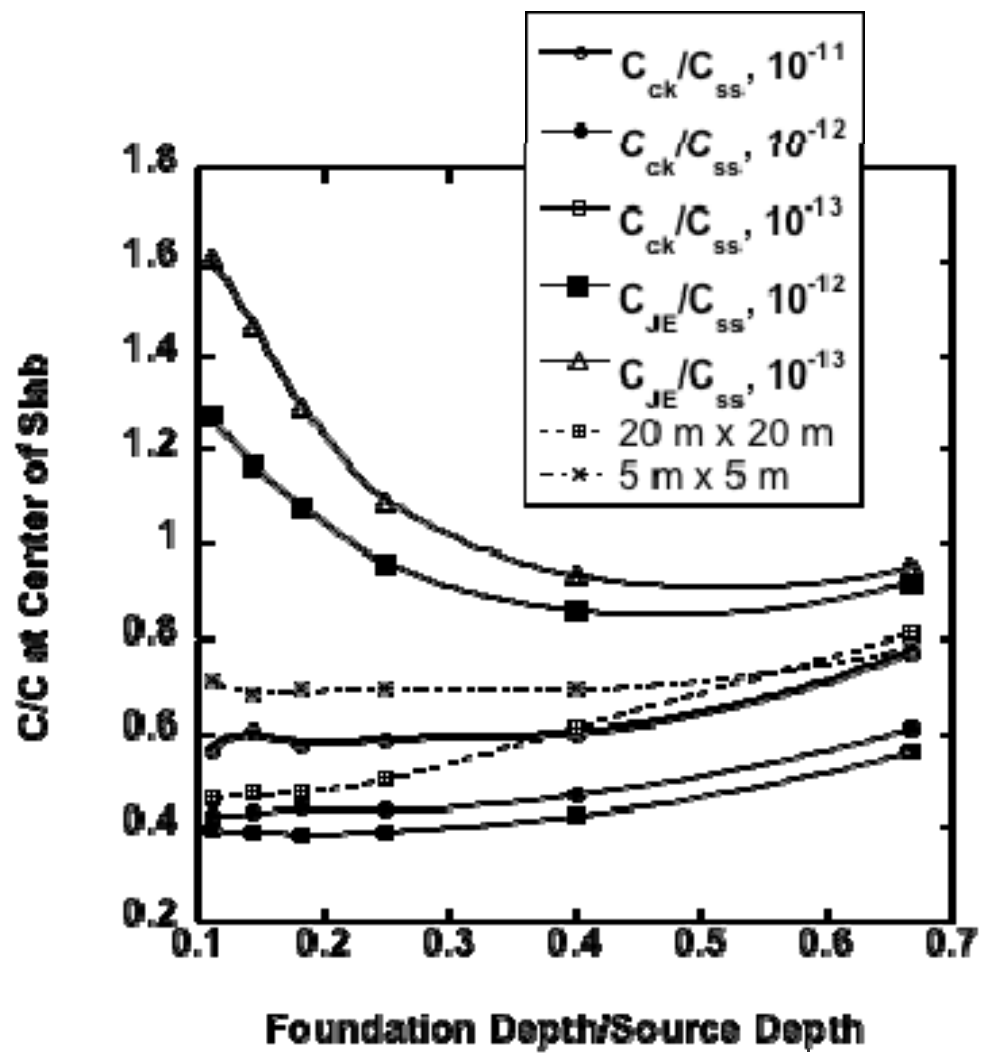

Figure 4: A comparison of the subslab concentrations at a perimeter crack and subslab center, for different soil permeabilities and source depths. Also shown is a comparison of the subslab concentrations from the Johnson-Ettinger model to the subslab center concentrations from the full three-dimensional model, for two soil permeabilities. All results are for $10 \mathrm{~m}$ x $10 \mathrm{~m}$ footprint except as noted. 
permeabilities of $10^{-11}, 10^{-12}$ and $10^{-13} \mathrm{~m}^{2}$. The significance of these results is that the subslab concentrations are not particularly sensitive to the subslab location, to within a factor of two or three. These results were obtained for a constant contaminant vapor soil diffusivity of $1 \times 10^{-6} \mathrm{~m}^{2} / \mathrm{s}$. This is true for a fairly wide range of source depth to foundation depth ratios. Also shown are results for $20 \mathrm{~m}$ x $20 \mathrm{~m}$ and $5 \mathrm{~m} \times 5 \mathrm{~m}$ footprint structures $\left(\mathrm{k}=10^{-11} \mathrm{~m}^{2}\right)$, and these confirm that the conclusion is not sensitive to building size for typical residential/small commercial buildings. In other words, in an area characterized by homogeneous soil, there would not be an expectation of orders of magnitude variation in subslab contaminant concentrations. This is entirely consistent with pictures such as Figure 1 that show generally uniformity of concentration beneath structures built atop homogeneous soils.

The implication of the above finding is that the prediction of contaminant entry rates through the foundation should not depend very strongly upon where the cracks in the slab may be located. Rather, the contaminant entry rate will depend more upon the pressure driving force, the total area of the cracks and how those cracks are distributed, because these determine the soil gas entry rate that carries the contaminant into the structure.

Again, the above is not intended to disregard the occasional field observations of widely varying subslab concentrations under the same structure. What this does mean is that such findings should only be expected where there are major subsurface features that create heterogeneity in the diffusion field, or that there exist variations in how well ventilated the subslab is.

It has recently been shown that the Johnson-Ettinger one-dimensional screening tool can often provide estimates of indoor air concentrations that are in reasonable agreement with the full 3-D analysis employed here. Figure 4 shows a reason why this is the case. The estimate of subslab contaminant concentration is quite close to that from the full 3-D analysis.

A separate calculation has been performed to illustrate the impact on contaminant entry rates of advection to diffusion. Sample results are shown in Figure 5 , for a $10 \mathrm{~m} \times 10 \mathrm{~m}$ structure with and without a $5 \mathrm{~m}$ wide impermeable paved apron around the building. All calculations are for homogeneous soil with a source at $8 \mathrm{~m}$ depth.

These results confirm that in high permeability soils, advection of contaminant with soil gas dominates the entry into the structure, whereas in low permeability (clay-type) soils, diffusional processes determine entry rates. Their relative contributions are similar, despite the fact that the structure with the surrounding paving has a $25 \%$ higher entry rate of contaminant at $10^{-12} \mathrm{~m}^{2}$ permeability. It is the slightly higher average contaminant concentration near the perimeter crack that determines this, which is an indication of the magnitude of impact of subslab concentration variations due to surrounding capping.

One additional point may be made when considering the results for the structure without surrounding paving. While not shown explicitly on Figure 5, at $10^{-14} \mathrm{~m}^{2}$ permeability, the contaminant entry rate is half that at $10^{-12} \mathrm{~m}^{2}$ permeability. This is because diffusion is a much slower process than advection, and the process has moved to completely diffusion controlled at $10^{-14} \mathrm{~m}^{2}$. 
The contaminant entry rate results for $10^{-11} \mathrm{~m}^{2}$ are an order of magnitude higher than those for $10^{-14} \mathrm{~m}^{2}$, which would lead to an order of magnitude higher indoor air concentration for the former compared to the latter. This difference has nothing to do with subslab concentrations, which are comparable in all the cases; it is merely a consequence of the well known fact that where advection is significant, much higher entry rates will be observed despite the similarity of subslab concentrations.

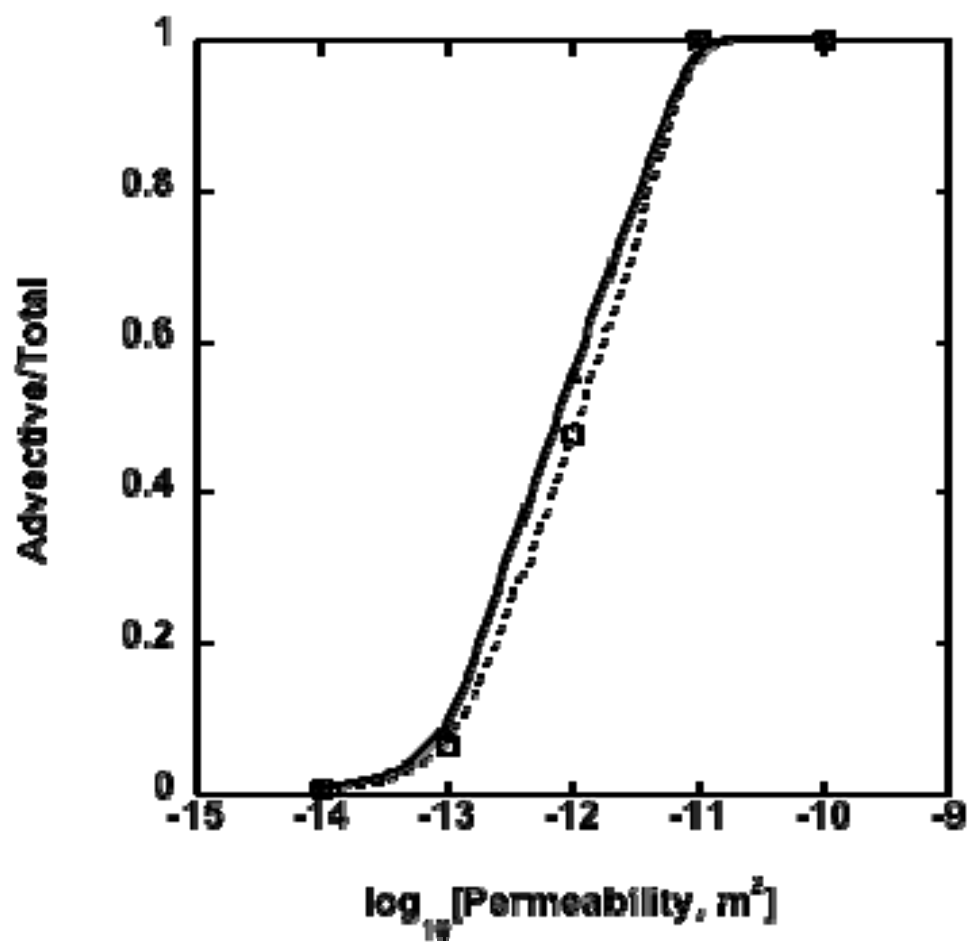

Figure 5: The relative contribution of advective contaminant transport to diffusive transport into a $10 \mathrm{~m} \times 10 \mathrm{~m}$ structure with (squares and dotted line) and without (triangles and solid line) a $5 \mathrm{~m}$ wide paved apron around the structure. Contaminant entry is through a perimeter crack.

\section{Conclusions}

The results of numerical modelling of the vapor intrusion process suggest that for structures built atop homogeneous soils, there should be little variation in subslab contaminant concentrations immediately beneath the building footprint, and that sampling at any one point should be as good as sampling at any other 
point. Existence of wide subslab concentration variations immediately implies complexity in the subsurface. Subslab concentrations by themselves do not indicate the potential for significant entry rate into a structure; advection greatly enhances the entry rate relative to diffusion, which may be the only mechanism of relevance in low permeability (clay-like) soils.

\section{References}

[1] Bozkurt, O., Pennell, K. G., Suuberg, E. M., Simulation of the vapor intrusion process for nonhomogeneous soils using a three-dimensional numerical model. Ground Water Monitoring and Remediation, 29 (1), pp 92-104, 2009.

[2] Pennell, K. G., Bozkurt, O., Suuberg, E. M., Development and application of a 3-D model for evaluating site-specific features on vapor intrusion rates in homogenous geologies. Journal of Air and Waste Management Association, 59, pp 447-460, 2009.

[3] Yao, Y., Pennell, K.G., Suuberg. E.M., Vapor intrusion in urban settings: effect of foundation features and source location. Procedia Environmental Sciences, 4, pp 245-249, 2011.

[4] Pennell, K.G., Suuberg, E.M. Vapor transport from soil and groundwater: numerical modeling approach (Chapter 4). Vapor Emission to Outdoor and Enclosed Spaces, ed. S. Saponaro, E. Sezenna, L. Bonomo, Nova Science Publishers, Inc.: New York, 2010.

[5] Johnson, P.C. Identification of critical parameters for the Johnson and Ettinger (1991) vapor intrusion model. American Petroleum Institute (API), Washington, D.C., Publication \#17, 2002.

[6] Abreu, L.D., Johnson, P.C., Effect of vapor source-building separation and building construction on soil vapor intrusion as studied with a threedimensional numerical model. Environmental Science and Technology, 39, pp 4550-4561, 2005.

[7] Yao, Y., Shen, R., Pennell, K.G., Suuberg. E.M., Comparison of the Johnson-Ettinger vapor intrusion screening model predictions with full three-dimensional model results. Environmental Science and Technology, 45, pp 2227-2235, 2011.

[8] Provoost, J., Bosman, A., Reijnders, L., Bronders, J., Touchant, K., Swartjes, F., Vapor intrusion from the vadose zone- seven algorithms compared. Jl. Soils Sediments, 10, pp 473-483, 2010.

[9] Provoost, J., Reijnders, L., Swartjes, F., Bronders, J., Seuntjens, P., Lijzen, J., Accuracy of seven vapor intrusion algorithms for VOC in groundwater. Jl. Soils Sediments, 9, pp 62-73, 2009.

[10] Turczynowicz, L., Robinson, N.I., Exposure assessment modelling for volatiles- towards an Australian indoor vapor intrusion model. Jl. of Toxicology and Environmental Health, Part A, 70, pp 1619-1634, 2007. 